\title{
Rotary and linear molecular motors driven by pulses of a chemical fuel
}

DOI:

10.1126/science.aao1377

\section{Document Version}

Accepted author manuscript

Link to publication record in Manchester Research Explorer

\section{Citation for published version (APA):}

Erbas-Cakmak, S., Fielden, S. D. P., Karaca, U., Leigh, D. A., McTernan, C. T., Tetlow, D. J., \& Wilson, M. R. (2017). Rotary and linear molecular motors driven by pulses of a chemical fuel. Science, 358(6361), 340-343. https://doi.org/10.1126/science.aao1377

\section{Published in:}

Science

\section{Citing this paper}

Please note that where the full-text provided on Manchester Research Explorer is the Author Accepted Manuscript or Proof version this may differ from the final Published version. If citing, it is advised that you check and use the publisher's definitive version.

\section{General rights}

Copyright and moral rights for the publications made accessible in the Research Explorer are retained by the authors and/or other copyright owners and it is a condition of accessing publications that users recognise and abide by the legal requirements associated with these rights.

\section{Takedown policy}

If you believe that this document breaches copyright please refer to the University of Manchester's Takedown Procedures [http://man.ac.uk/04Y6Bo] or contact uml.scholarlycommunications@manchester.ac.uk providing relevant details, so we can investigate your claim.

\section{OPEN ACCESS}




\title{
Rotary and linear molecular motors driven by pulses of a chemical fuel
}

\author{
Sundus Erbas-Cakmak, Stephen D. P. Fielden, Ulvi Karaca, David A. Leigh*, \\ Charlie T. McTernan, Daniel J. Tetlow and Miriam R. Wilson \\ School of Chemistry, University of Manchester, Oxford Road, Manchester, M13 9PL, UK \\ *Correspondence to: david.leigh@manchester.ac.uk
}

\begin{abstract}
Many biomolecular motors catalyze the hydrolysis of chemical fuels, such as adenosine triphosphate (ATP), and use the energy released to direct motion through information ratchet mechanisms. Here we describe chemically-driven artificial rotary and linear molecular motors that operate through a fundamentally different type of mechanism. The directional rotation of [2]- and [3]catenane rotary molecular motors, and the transport of substrates away from equilibrium by a linear molecular pump, are induced by acid-base oscillations. The changes simultaneously switch the binding site affinities and the labilities of barriers on the track, creating an energy ratchet. The linear and rotary molecular motors are driven by aliquots of a chemical fuel, trichloroacetic acid. A single fuel pulse generates $360^{\circ}$ unidirectional rotation of up to $87 \%$ of crown ethers in a [2]catenane rotary motor.
\end{abstract}

One Sentence Summary: Rotary molecular motors and a linear molecular pump are driven by pulses of a chemical fuel, producing $\mathrm{CHCl}_{3}$ and $\mathrm{CO}_{2}$ as the only byproducts of an energy ratchet mechanism.

The conversion of chemical energy into molecular-level directional motion enables biological systems to perform a myriad of functions. Directional movement has been demonstrated in artificial molecular machines (1-4), using photoexcitation (5-11) and/or the sequential addition of chemical reagents (12-22), and an autonomous chemically-driven molecular rotary motor that operates through a bio-inspired (23) information ratchet mechanism has been described $(24,25)$. Here we report on an alternative class of ratchet mechanism, based on acid-base oscillations, that powers both rotary and linear molecular motors. The system uses the change in relative binding affinity of macrocycles for different binding sites on circular or linear tracks and a gating system based on dynamic covalent chemistry (26), which are both affected by switching between acidic and basic conditions. The combination of these processes causes directional rotation of the components in [2]- and [3]catenane rotary motors and the generation of out-of-equilibrium concentrations of a substrate using a linear molecular pump. The acid-base oscillations can be induced by aliquots of trichloroacetic acid $\left(\mathrm{Cl}_{3} \mathrm{CCO}_{2} \mathrm{H}\right)$, a chemical fuel that undergoes basepromoted decarboxylation (26), generating chloroform $\left(\mathrm{CHCl}_{3}\right)$ and carbon dioxide $\left(\mathrm{CO}_{2}\right)$ as the only waste products of motor operation.

In an energy ratchet mechanism, a Brownian particle is inexorably transported with net directionality without information regarding the substrate (e.g. its position or velocity) 
influencing the process $(1,28,29)$. One of several ways that this can be accomplished is by repeatedly switching which of two maxima is the highest and which of two minima the lowest on a fluctuating potential energy surface (Fig. 1A). We sought to simultaneously switch the barrier heights (which determine the kinetics of movement in each direction) and binding site affinities (which provide a driving force for transport) back-and-forth to produce a motor-mechanism requiring only a single chemical input. The reversible protonation of an amine group can be used to switch the position of crown ethers in rotaxane-based molecular shuttles (30), while potential barriers based on bulky hydrazones and disulfides have orthogonal labilities in acid and base (16, 20). We first demonstrated that these two processes can operate simultaneously with model rotaxanes [Supplementary Material (SM) Section 4.1, Fig. S1] and then applied them to directional rotation of the components of a [2]catenane rotary motor, 1 (Fig. 1).
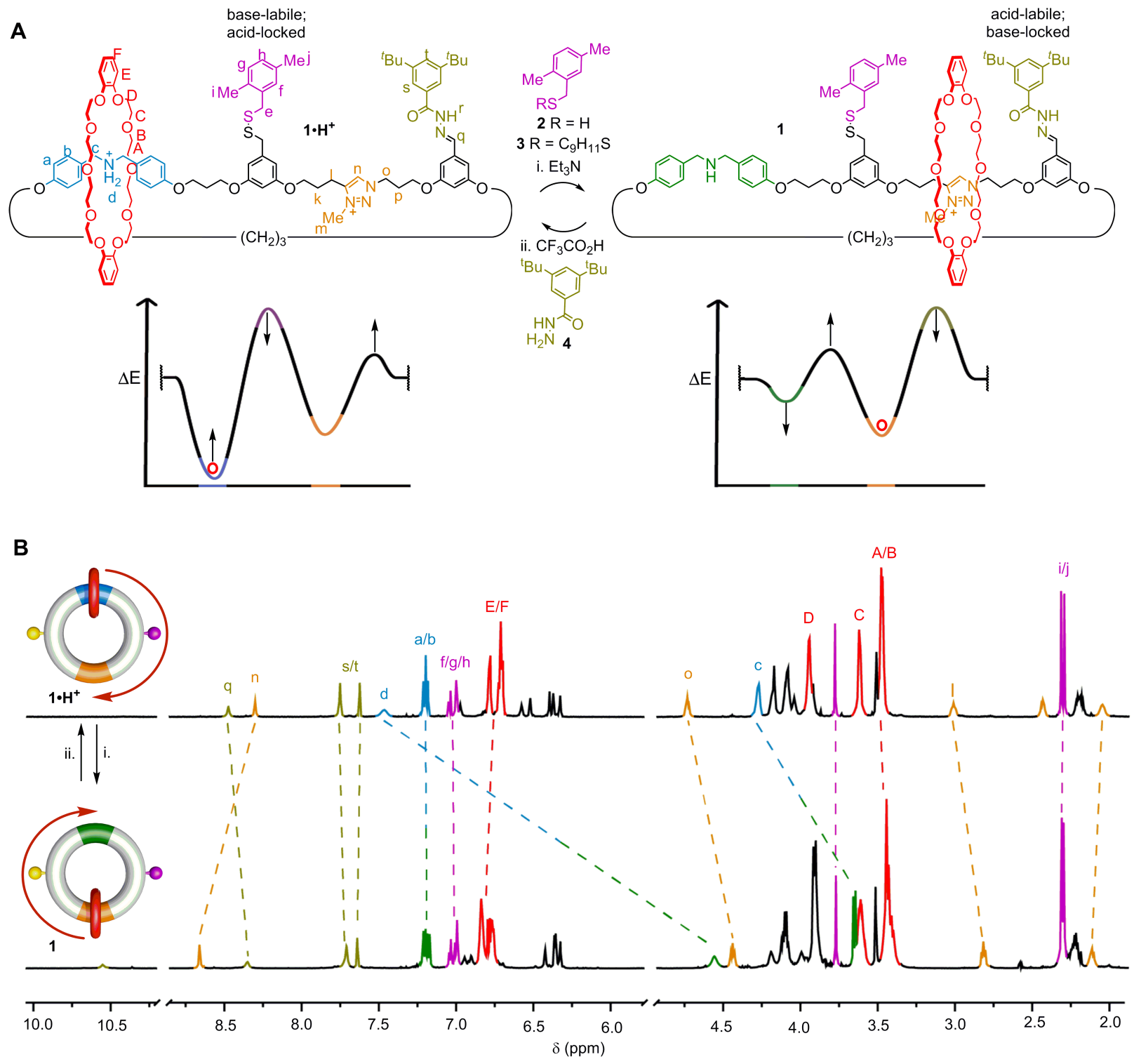

Fig. 1. Stepwise operation of $[2]$ catenane rotary motor $\mathbf{1} / \mathbf{1}\left[\mathbf{H}^{+}\right]$. (A) Reagents and conditions: (i) [2]Catenane motor $\mathbf{1} \cdot \mathrm{H}^{+}(2.4 \mu \mathrm{mol}, 2.6 \mathrm{mM})$, thiol $2(12 \mu \mathrm{mol}), \mathrm{Et}_{3} \mathrm{~N}(36 \mu \mathrm{mol})$, disulfide 3 (12 $\mu \mathrm{mol}), \mathrm{CD}_{2} \mathrm{Cl}_{2}$, room temperature (r.t.), $94 \%$ of macrocycles on triazolium site. (ii) 
Hydrazide $4(2.4 \mu \mathrm{mol}), \mathrm{CF}_{3} \mathrm{CO}_{2} \mathrm{H}(60 \mu \mathrm{mol}), \mathrm{CD}_{2} \mathrm{Cl}_{2}$, r.t., $>99 \%$ of macrocycles on dibenzylammonium site. Potential energy diagrams: Under acidic conditions the left-hand minimum is the lowest and the left-hand maximum is the highest; under basic conditions the right-hand minimum is lowest and the right-hand maximum is highest. This energy ratchet mechanism inexorably transports a Brownian particle, here the crown ether, in a clockwise direction around the track. (B) Partial ${ }^{1} \mathrm{H}$ NMR spectra $\left(600 \mathrm{MHz}, \mathrm{CD}_{2} \mathrm{Cl}_{2}, 298 \mathrm{~K}\right)$ of [2] catenane $\mathbf{1} \cdot \mathrm{H}^{+}$and $\mathbf{1}$.

[2]Catenane $\mathbf{1} \cdot \mathrm{H}^{+}$was synthesized in 24 steps (SM, Section 4.4), a key step involving macrocyclization of an intermediate pseudo[2]rotaxane (SM, Fig. S20). In order to isolate and characterize the motor in different positional states, we first operated it through sequential additions of base and acid (Fig. 1 and SM, Section 4.4.4). The crown ether resides on the protonated dibenzylammonium site (shown in blue) in $\mathbf{1} \cdot \mathrm{H}^{+}$. Upon addition of excess triethylamine $\left(\mathrm{Et}_{3} \mathrm{~N}\right)$, the dibenzylammonium station is deprotonated (green in 1) making the triazolium group (orange) the thermodynamically preferred binding site in 1 (Fig. 1A, step (i)) (31). Under these basic conditions the hydrazone blocking group (olive) is kinetically inert and blocks movement of the macrocycle in that direction, whereas the disulfide group (purple) exchanges with disulfides (3) in the bulk through thiolate catalysis (enabled by 2) allowing passage of the macrocycle to the triazolium group via the right-hand pathway (i.e. a clockwise $180^{\circ}$ turn). The ${ }^{1} \mathrm{H}$ NMR chemical shifts of several protons (e.g. $\mathrm{H}_{\mathrm{c}}$ of the dibenzylamine/ammonium group and $\mathrm{H}_{\mathrm{o}}$ of the methylene adjacent to a triazolium nitrogen atom) are diagnostic of the position of the crown ether on the track in both $\mathbf{1}$ and $\mathbf{1} \cdot \mathrm{H}^{+}$(Fig. 1B).

Trifluoroacetic acid $\left(\mathrm{CF}_{3} \mathrm{CO}_{2} \mathrm{H}\right)$ was then added until the solution became acidic (Fig. 1A, step (ii)). Under these conditions the dibenzylamine site is re-protonated and once again becomes the thermodynamically preferred binding site for the crown ether. The disulfide barrier is locked under acidic conditions, whereas the hydrazone undergoes exchange (with 4), and so the macrocycle returns to the dibenzylammonium site via the left-hand pathway (i.e. another clockwise $180^{\circ}$ turn). The model rotaxane studies confirm that the crown ether cannot pass a disulfide barrier under acidic conditions or a hydrazone barrier under basic conditions (SM, Sections 4.1, 4.2.7 and 4.3.7). The ring movements in 1 are highly correlated: $93 \%$ of crown ethers starting on the dibenzylammonium site complete one $360^{\circ}$ directional rotation after one acid-base cycle (based on ${ }^{1} \mathrm{H}$ NMR integration of Fig. 1 steps (i) and (ii)), with the mechanism ensuring that no motors rotate more than once from each fuel pulse.

During the macrocyclization reaction to form [2]catenane 1, a [3]catenane (5) with two crown ethers interlocked onto a large ring featuring two ammonium and two triazolium binding sites was also isolated (SM, Section 4.5, Fig. S23). [3]Catenane 5 also functions as a chemicallydriven rotary motor, with one full rotation requiring two cycles of acid-base addition to ratchet both crown ethers around the larger ring in one direction (Fig. 2 and SM, Section 4.5.2). From the efficiencies of Fig. 2 steps (i)-(iv), approximately $65 \%$ of crown ethers starting on a dibenzylammonium site in $5 \cdot 2 \mathrm{H}^{+}$undergo $360^{\circ}$ directional rotation after two cycles, in a 'follow-the-leader' manner. 


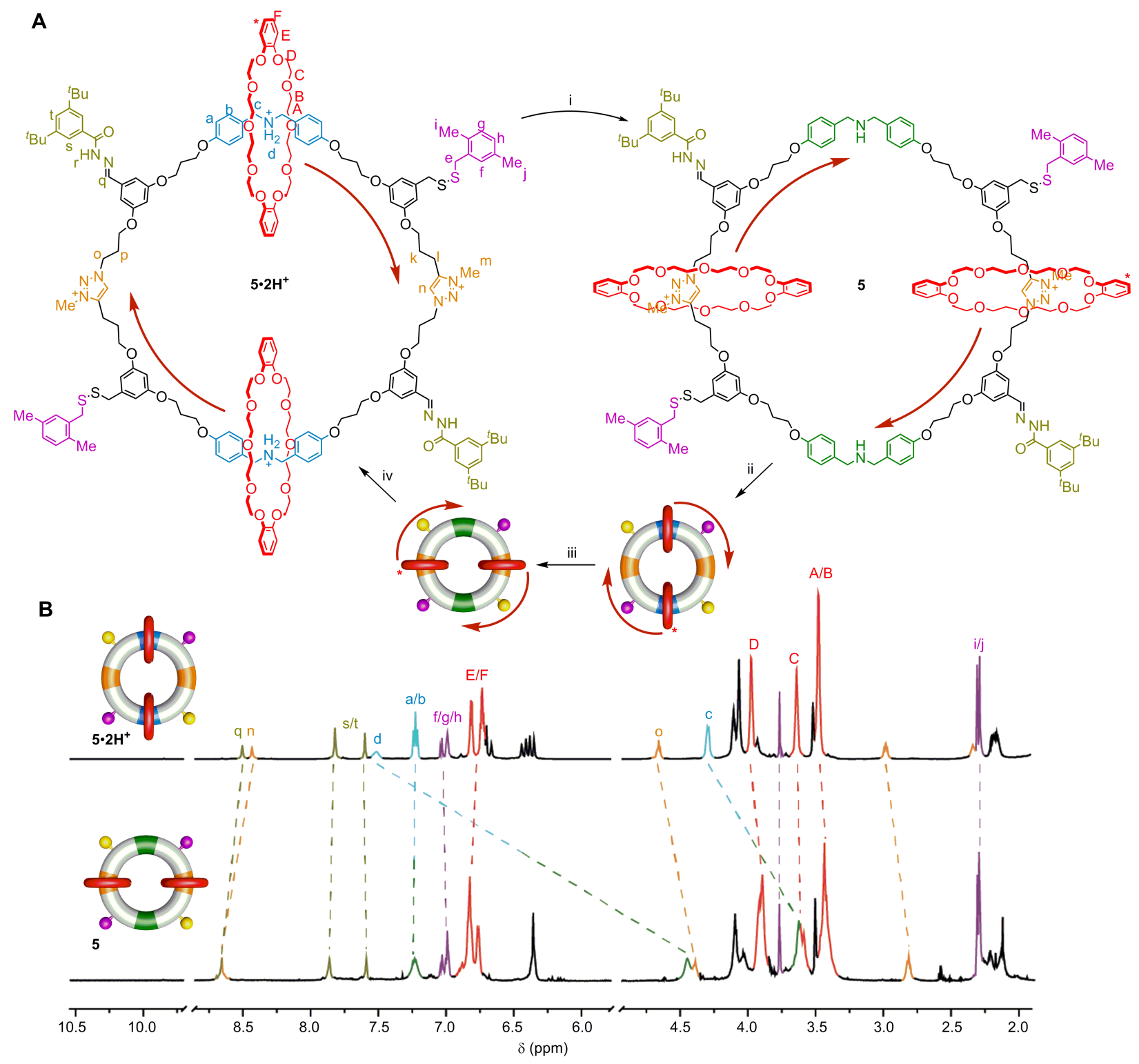

Fig. 2. Stepwise operation of $[3]$ catenane rotary motor $5 / 5\left[2 \mathbf{H}^{+}\right]$. (A) Reagents and conditions: (i) [3]Catenane $\mathbf{5} \cdot 2 \mathrm{H}^{+}(1.2 \mu \mathrm{mol}, 2 \mathrm{mM}), \mathrm{Et}_{3} \mathrm{~N}(36 \mu \mathrm{mol})$, thiol 2 (24 $\left.\mu \mathrm{mol}\right)$, disulfide 3 (120 $\mu \mathrm{mol})$, Hydrazide $4(2.4 \mu \mathrm{mol}), \mathrm{CD}_{2} \mathrm{Cl}_{2}, 94 \%$. (ii) $\mathrm{CF}_{3} \mathrm{CO}_{2} \mathrm{H}(60 \mu \mathrm{mol}), 91 \%$. (iii) $\mathrm{Et}_{3} \mathrm{~N}(60 \mu \mathrm{mol}), 86 \%$. (iv) $\mathrm{CF}_{3} \mathrm{CO}_{2} \mathrm{H}(120 \mu \mathrm{mol}), 88 \%$. The star symbol differentiates the movement of the (indistinguishable) macrocycles in the mechanism. (B) Partial ${ }^{1} \mathrm{H}$ NMR spectra $\left(600 \mathrm{MHz}, \mathrm{CD}_{2} \mathrm{Cl}_{2}, 298 \mathrm{~K}\right)$ of [3]catenane $\mathbf{5} \cdot 2 \mathrm{H}^{+}$and $\mathbf{5}$.

In the stepwise operation of $\mathbf{1}$ and $\mathbf{5}$, increasing amounts of acid and base have to be added, forming salt byproducts as waste (SM, Sections 4.4.4 and 4.5.2). Recently, the base-catalyzed decarboxylation of 2-cyano-2-phenylpropanoic acid was used to switch between the well-defined protonated co-conformation of a [2]catenane and a de-protonated state with minimal favorable interactions between the rings (32). We investigated whether a similar process could be used to drive directional rotations in molecular motors. As decarboxylation of 2-cyano-2- 
phenylpropanoic acid results in 2-phenylpropanonitrile, a potentially persistant organic waste product, we instead utilized trichloroacetic acid $\left(\mathrm{Cl}_{3} \mathrm{CCO}_{2} \mathrm{H}\right)$, which undergoes efficient $\mathrm{Et}_{3} \mathrm{~N}$ catalyzed decarboxylation at room temperature to give chloroform $\left(\mathrm{CHCl}_{3}\right)$, a common and volatile solvent, and carbon dioxide $\left(\mathrm{CO}_{2}\right)$ (27) (Fig. 3). In principle as little as one molar equivalent of fuel is required to power each chemically-fuelled cycle (32), but the acid-catalyzed hydrazone barrier exchange is slow at the dilute $(\mathrm{mM})$ concentrations employed here and so it proved convenient to use excess $\mathrm{Cl}_{3} \mathrm{CCO}_{2} \mathrm{H}$ for motor operation (33). We also found it helpful to add 2-methyl-2-butene for long motor runs to scavenge trace byproducts from $\mathrm{CHCl}_{3}$ decomposition (34).

An initial 4:1 acid:base ratio (80:19:1 trichloroacetic acid:triethylamine:1) in acetonitrile protonates the dibenzylammonium site in the [2]catenane motor and catalyzes hydrazone barrier exchange leading to $180^{\circ}$ directional rotation of $90 \%$ of the crown ethers originally at the triazolium group, forming $\mathbf{1} \cdot \mathrm{H}^{+}$after $15 \mathrm{~h}$ (Fig. 3). While the acid-promoted rotation is occurring, triethylamine catalyzes decarboxylation of the trichloroacetic acid until, after $17 \mathrm{~h}$, almost all of the trichloroacetic acid has been converted to $\mathrm{CO}_{2}$ and $\mathrm{CHCl}_{3}$ and the reaction mixture has become sufficiently basic to deprotonate the dibenzylammonium group and promote disulfide exchange, as required for the second $180^{\circ}$ directional rotation of the motor (the combined quantity of $\mathrm{Et}_{3} \mathrm{~N}$ and $\mathrm{Et}_{3} \mathrm{NH}^{+}$remains constant; as the fuel decarboxylates progressively more $\mathrm{Et}_{3} \mathrm{~N}$ exists as the free base). A single pulse of the chemical fuel drives autonomous $360^{\circ}$ rotation of up to $87 \%$ of the crown ethers in 1 . At $\mathrm{mM}$ concentrations of motor the first unidirectional rotation is complete within $1 \mathrm{~h}$ at $60^{\circ} \mathrm{C}(33)$. Additional pulses of fuel cause further rotations with little or no change in fidelity of the motor mechanism, although the time required to complete each rotation increases as dilution of the reaction mixture slows the rate of hydrazone and disulfide exchange (Fig. 3B). Analogous operation of [3]catenane 5 leads to up to $82 \%$ of crown ethers directionally advancing $180^{\circ}$ in response to each fuel pulse. 
A

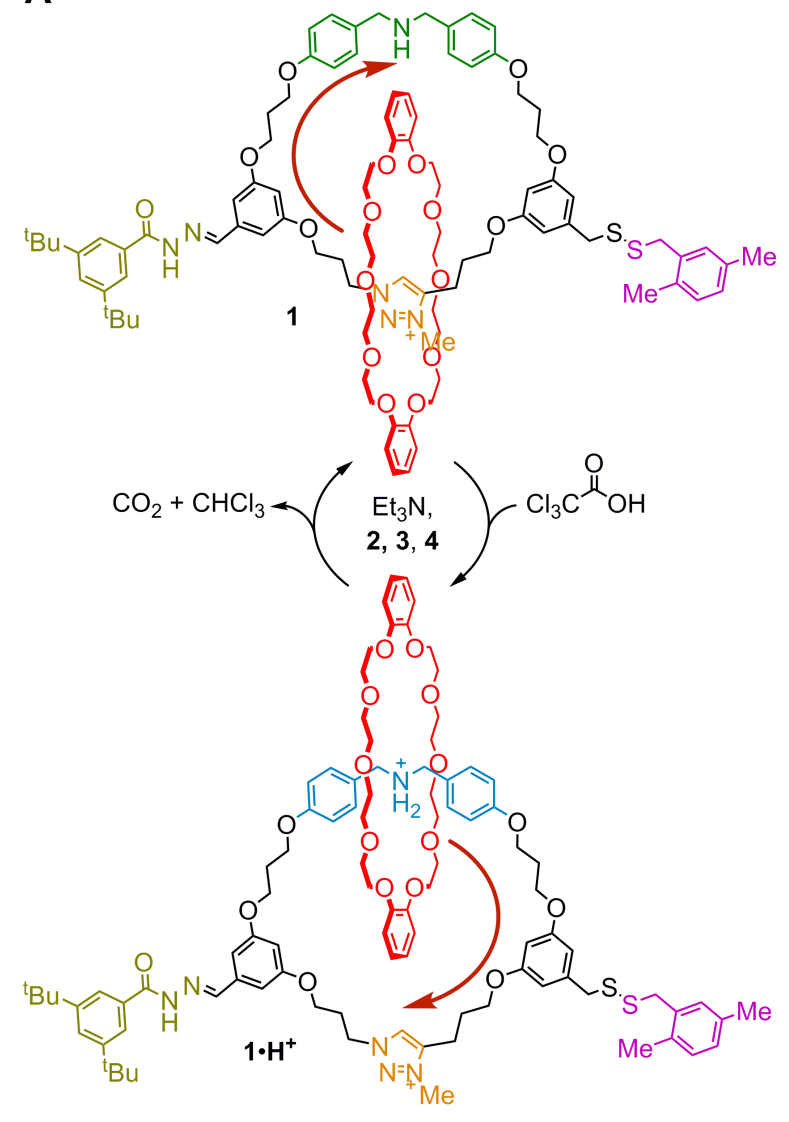

B

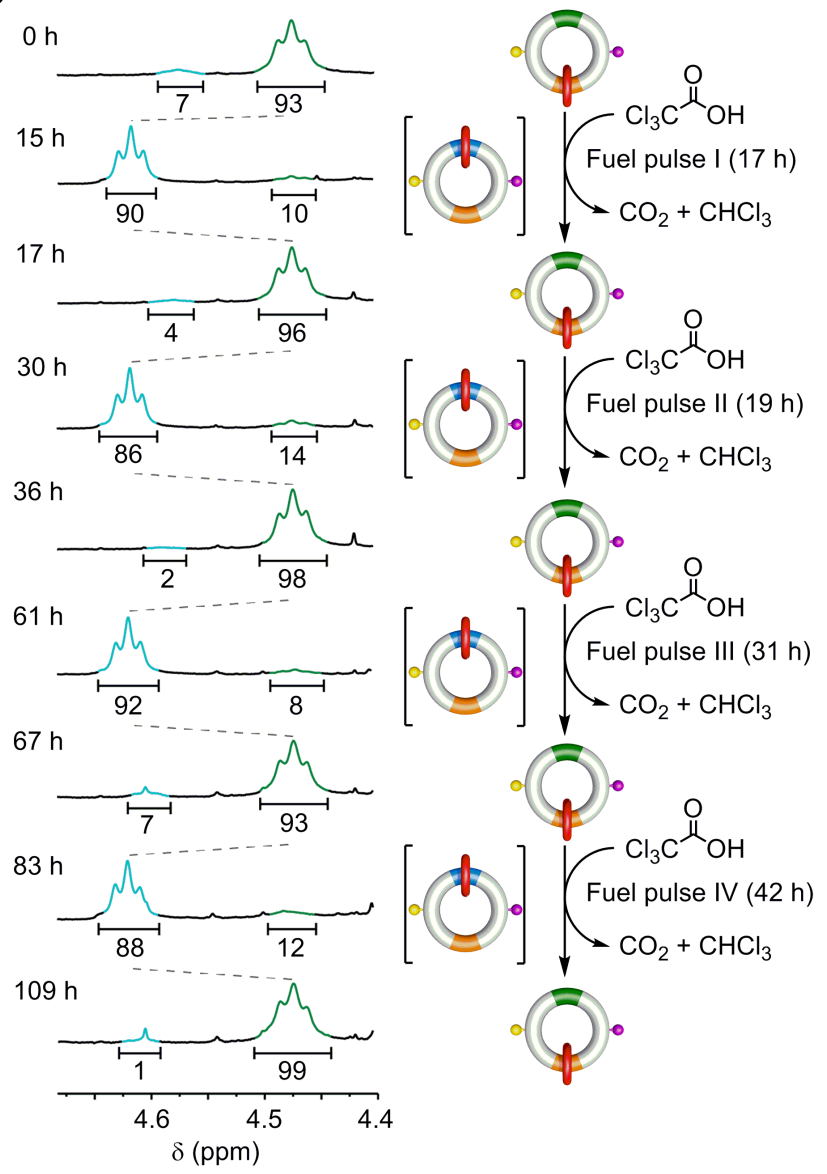

Fig. 3. Operation of rotary motor $1 / 1\left[\mathrm{H}^{+}\right]$using pulses of a chemical fuel. (A) Reagents and conditions: [2]Catenane $1(1.2 \mu \mathrm{mol}, 2 \mathrm{mM}), \mathrm{Et}_{3} \mathrm{~N}(23 \mu \mathrm{mol})$, thiol $\mathbf{2}(12 \mu \mathrm{mol})$, disulfide 3 (60 $\mu \mathrm{mol})$, hydrazide 4 (4.2 $\mu \mathrm{mol})$, 2-methyl-2-butene $(5.4 \mu \mathrm{mol}), \mathrm{CD}_{3} \mathrm{CN}$. Each pulse of fuel contained $96 \mu \mathrm{mol}$ of trichloroacetic acid. (B) ${ }^{1} \mathrm{H} \mathrm{NMR}$ signal $\left(600 \mathrm{MHz}, \mathrm{CD}_{3} \mathrm{CN}, 298 \mathrm{~K}\right)$ of proton $\mathrm{H}_{\mathrm{o}}$ in [2] catenane $\mathbf{1}$ over four pulses of chemical fuel. Times shown are for operations at room temperature (left: cumulative time; right: time taken for that pulse). At $60{ }^{\circ} \mathrm{C}$ the first pulse cycle is complete within $1 \mathrm{~h} \mathrm{(33)}$.

The same mechanism was used to drive a molecular pump. Linear motor $\mathbf{6}$ features the same ratcheting unit as rotary motors 1 and 5 (Fig. 4). The thread has hydrazone groups at either end and dibenzylamine/ammonium sites partitioned by disulfide barriers from an internal compartment containing two triazolium rings. Although triazolium groups act as modest affinity binding sites for crown ethers within interlocked structures, the binding is too weak to promote threading (35) and so despite being local energy minima, crown ethers binding to those sites (or non-protonated amine sites) are not global low energy species (Fig. 4B). However, without the triazolium groups present on the axle we found that the internal compartment was too high in energy for crown ethers to be efficiently displaced from the dibenzylamine region during ratcheting. The ratcheting units are capped with adamantyl groups, small enough to allow 
threading of the crown ether macrocycle when the adjacent hydrazone group is labile, but large enough to prevent dethreading when the hydrazone is locked in place.

In the operation of pump $\mathbf{6}$ a single pulse of trichloroacetic acid fuel generated a rotaxane with an average of 1.9 crown ether macrocycles on the axle (SM, Section 4.7.3). Mass spectrometry showed that after one cycle of operation no thread had $>2$ macrocycles, consistent with the initial cycle of an energy ratchet mechanism. After a second pulse of fuel an average of $3.1 \pm 0.1$ (based on ${ }^{1} \mathrm{H}$ NMR integration) crown ethers had been pumped from solution onto each axle, with mass spectroscopy confirming no thread having $>4$ macrocycles. After four rounds of operation each motor-molecule had pumped an average of 3.7 macrocycles from solution, forming predominantly [5]rotaxane 8. The four crown ethers in $\mathbf{8}$ are all in higher energy states than unthreaded crown ethers (Fig. 4B). With an analogous thread bearing the same binding sites but no barriers, pulses of trichloroacetic acid in triethylamine led initially to two crown ethers on the thread, but these dethreaded following trichloroacetic acid decarboxylation, leaving only the original unthreaded components. Other than with 6, we were unable to thread more than two crown ethers onto axles of this type with only two dibenzylammonium sites, and no crown ethers onto axles with unprotonated dibenzylamine sites. 


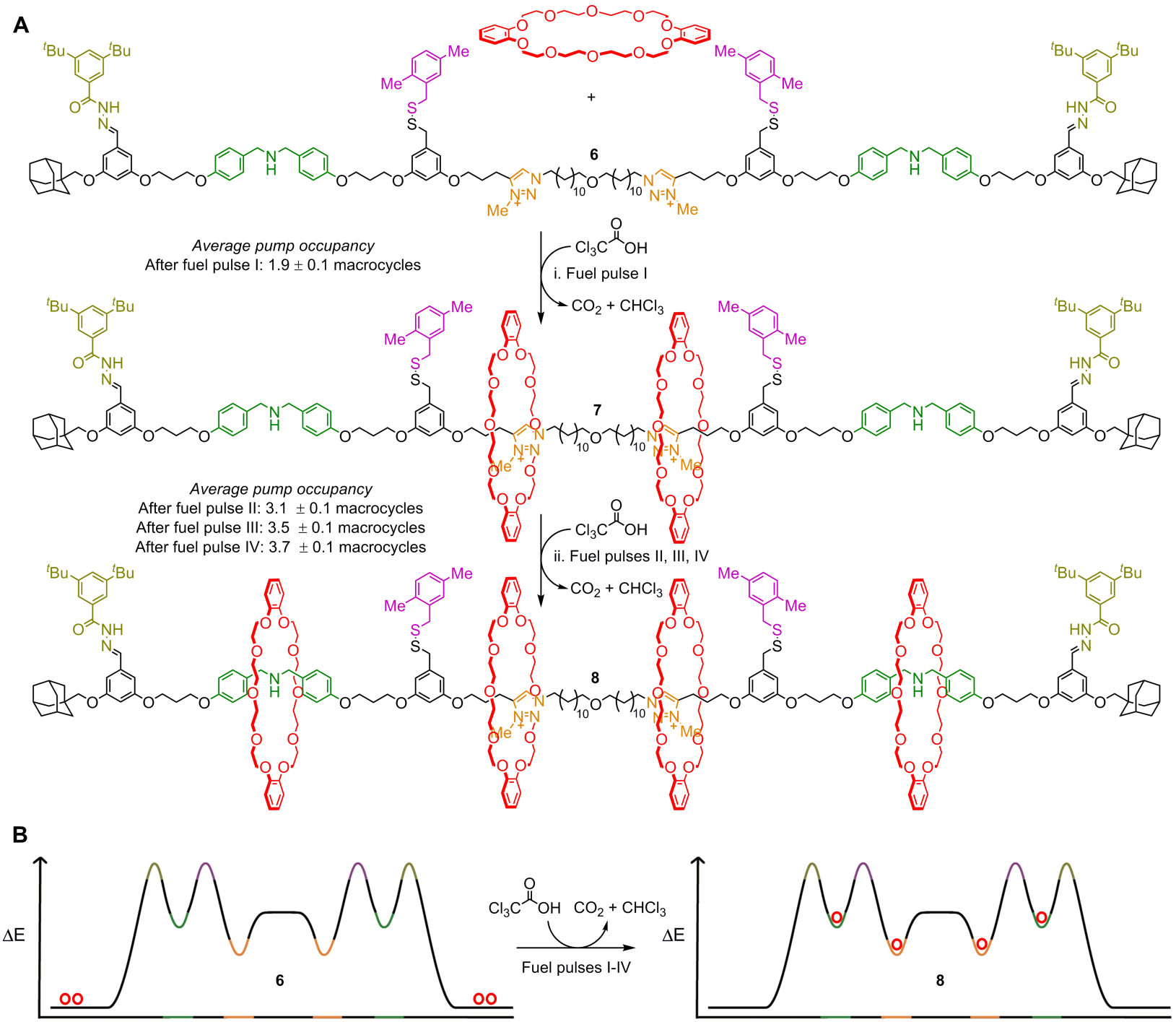

Fig. 4. Operation of molecular pump 6 with a pulsed chemical fuel. (A) Reagents and conditions: Pump $6(0.6 \mu \mathrm{mol}, 1 \mathrm{mM})$, crown ether $(0.18 \mathrm{mmol})$, thiol 2 (12 $\mu \mathrm{mol})$, disulfide 3 (60 $\mu \mathrm{mol}), \mathrm{Et}_{3} \mathrm{~N}(24 \mu \mathrm{mol})$, hydrazide $4(4.2 \mu \mathrm{mol})$, trichloroacetic acid $(120 \mu \mathrm{mol})$, $\mathrm{CD}_{2} \mathrm{Cl}_{2}: \mathrm{CD}_{3} \mathrm{CN}$ 9:1. (B) Potential energy diagram for the pumping of the crown ether from bulk solution to form [5]rotaxane $\mathbf{8}$.

The use of pulses of chemical fuel to directionally transport components and substrates via an energy ratchet mechanism is operationally simple, effective, generates relatively innocuous waste products, and can function in a range of rotary and linear molecular motor and pump designs. The motor-movements are correlated by the pulsing of fuel, with up to $87 \%$ of molecules of 1 completing one directional $360^{\circ}$ rotation in response to each addition of chemical fuel and no motors directionally rotating more than the number of aliquots of fuel added. We anticipate that such a generally applicable motor-mechanism may prove useful in powering task performance in molecular nanotechnology. 


\section{References and Notes:}

1. S. Erbas-Cakmak, D. A. Leigh, C. T. McTernan, A. L. Nussbaumer, Artificial molecular machines. Chem. Rev. 115, 10081-10206 (2015).

2. J. M. Abendroth, O. S. Bushuyev, P. S. Weiss, C. J. Barrett, Controlling motion at the nanoscale: Rise of the molecular machines. ACS Nano 9, 7746-7768 (2015).

3. S. Kassem, T. van Leeuwen, A. S. Lubbe, M. R. Wilson, B. L. Feringa, D. A. Leigh, Artificial molecular motors. Chem. Soc. Rev. 46, 2592-2621 (2017).

4. C. Pezzato, C. Cheng, J. F. Stoddart, R. D. Astumian, Mastering the non-equilibrium assembly and operation of molecular machines. Chem. Soc. Rev. Advance Article, 10.1039/C7CS00068E (2017).

5. N. Koumura, R. W. J. Zijlstra, R. A. van Delden, N. Harada, B. L. Feringa, Light-driven monodirectional molecular rotor. Nature 401, 152-155 (1999).

6. V. Serreli, C.-F. Lee, E. R. Kay, D. A. Leigh, A molecular information ratchet. Nature 445, 523-527 (2007).

7. L. Greb, J.-M. Lehn, Light-driven molecular motors: Imines as four-step or two-step unidirectional rotors. J. Am. Chem. Soc. 136, 13114-13117 (2014).

8. G. Ragazzon, M. Baroncini, S. Silvi, M. Venturi, A. Credi, Light-powered autonomous and directional molecular motion of a dissipative self-assembling system. Nat. Nanotech. 10, 70-75 (2014).

9. M. Guentner, M. Schildhauer, S. Thumser, P. Mayer, D. Stephenson, P. J. Mayer, H. Dube, Sunlight-powered $\mathrm{kHz}$ rotation of a hemithioindigo-based molecular motor. Nat. Commun. 6, 8406 (2015).

10. Q. Li, G. Fuks, E. Moulin, M. Maaloum, M. Rawiso, I. Kulic, J. T. Foy, N. Giuseppone, Macroscopic contraction of a gel induced by the integrated motion of light-driven molecular motors. Nat. Nanotech. 10, 161-165 (2015).

11. P. Štacko, J. C. M. Kistemaker, T. van Leeuwen, M.-C. Chang, E. Otten, B. L. Feringa. Locked synchronous rotor motion in a molecular motor. Science 356, 964-968 (2017).

12. D. A. Leigh, J. K. Y. Wong, F. Dehez, F. Zerbetto, Unidirectional rotation in a mechanically interlocked molecular rotor. Nature 424, 174-179 (2003).

13. J. V. Hernández, E. R. Kay, D. A. Leigh, A reversible synthetic rotary molecular motor. Science 306, 1532-1537 (2004).

14. S. P. Fletcher, F. Dumur, M. M. Pollard, B. L. Feringa, A reversible, unidirectional molecular rotary motor driven by chemical energy. Science 310, 80-82 (2005).

15. M. N. Chatterjee, E. R. Kay, D. A. Leigh, Beyond switches: Ratcheting a particle energetically uphill with a compartmentalized molecular machine. J. Am. Chem. Soc. 128, 40584073 (2006).

16. M. von Delius, E. M. Geertsema, D. A. Leigh, A synthetic small molecule that can walk down a track. Nat. Chem. 2, 96-101 (2010). 
17. M. J. Barrell, A. G. Campaña, M. von Delius, E. M. Geertsema, D. A. Leigh, Light-driven transport of a molecular walker in either direction along a molecular track. Angew. Chem. Int. Ed. 50, 285-290 (2011).

18. G. Haberhauer, A molecular four-stroke motor. Angew. Chem. Int. Ed. 50, 6415-6418 (2011).

19. C. Cheng, P. R. McGonigal, S.T. Schneebeli, H. Li, N. A. Vermeulen, C. Ke, J. F. Stoddart, An artificial molecular pump. Nat. Nanotech. 10, 547-553 (2015).

20. S. Kassem, A. T. L. Lee, D. A. Leigh, A. Markevicius, J. Solà, Pick-up, transport and release of a molecular cargo using a small-molecule robotic arm. Nat. Chem. 8, 138-143 (2016).

21. B. S. L. Collins, J. C. M. Kistemaker, E. Otten, B. L. Feringa, A chemically powered unidirectional rotary molecular motor based on a palladium redox cycle. Nat. Chem. 8, 860-866 (2016).

22. Z. Meng, J.-F. Xiang, C.-F. Chen, Directional molecular transportation based on a catalytic stopper-leaving rotaxane system. J. Am. Chem. Soc. 138, 5652-5658 (2016).

23. R. D. Astumian, How molecular motors work - insights from the molecular machinist's toolbox: the Nobel prize in Chemistry 2016. Chem. Sci. 8, 840-845 (2017).

24. M. R. Wilson, J. Solà, A. Carlone, S. M. Goldup, N. Lebrasseur, D. A. Leigh, An autonomous chemically fuelled small-molecule motor. Nature 534, 235-240 (2016).

25. R. D. Astumian, Artificial molecular motors: Running on information. Nat. Nanotech. 11, 582-583 (2016).

26. S. J. Rowan, S. J. Cantrill, G. R. L. Cousins, J. K. M. Sanders, J. F. Stoddart, Dynamic covalent chemistry. Angew. Chem. Int. Ed. 41, 898-952 (2002).

27. B. R. Brown, The mechanism of thermal decarboxylation. Quart. Rev. (London) 5, 131-146 (1951).

28. R. D. Astumian, I. Derényi, Fluctuation driven transport and models of molecular motors and pumps. Eur. Biophys. J. 27, 474-489 (1998).

29. E. R. Kay, D. A. Leigh, F. Zerbetto. Synthetic molecular motors and mechanical machines. Angew. Chem. Int. Ed. 46, 72-191 (2007).

30. R. A. Bissell, E. Córdova, A. E. Kaifer, J. F. Stoddart, A chemically and electrochemically switchable molecular shuttle, Nature 369, 133-137 (1994).

31. F. Coutrot, A focus on triazolium as a multipurpose molecular station for $\mathrm{pH}$-sensitive interlocked crown-ether-based molecular machines. ChemistryOpen 4, 556-576 (2015).

32. J. A. Berrocal, C. Biagini, L. Mandolini, S. Di Stefano, Coupling of the decarboxylation of 2cyano-2-phenylpropanoic acid to large-amplitude motions: a convenient fuel for an acid-baseoperated molecular switch. Angew. Chem. Int. Ed. 55, 6997-7001 (2016).

33. Increasing the temperature and/or concentration reduces the time needed for each motor cycle.

34. B. S. Bal, W. E. Childers, Jr., H. W. Pinnick, Oxidation of $\alpha, \beta$-unsaturated aldehydes. Tetrahedron 37, 2091-2096 (1981). 
35. S. Chao, C. Romuald, K. Fournel-Marotte, C. Clavel, F. Coutrot, A strategy utilizing a recyclable macrocycle transporter for the efficient synthesis of a triazolium-based [2]rotaxane. Angew. Chem. Int. Ed. 53, 6914-6919 (2014).

36. H. Zheng, Y. Li, C. Zhou, Y. Li, W. Yang, W. Zhou, Z. Zuo, H. Liu, Synthesis of a [2]rotaxane incorporating a "magic sulfur ring" by the thiol-ene click reaction. Chem. Eur. J. 17, 2160-2167 (2011).

37. B. Lewandowski, G. De Bo, J. W. Ward, M. Papmeyer, S. Kuschel, M. J. Aldegunde, P. M. E. Gramlich, D. Heckmann, S. M. Goldup, D. M. D'Souza, A. E. Fernandes, D. A. Leigh, Sequence-specific peptide synthesis by an artificial small-molecule machine. Science 339, 189193 (2013).

38. K. Osakada, Y. Takenaka, I. Yamaguchi, T. Yamamoto, Preparation of $\alpha, \omega$-diols of long carbon chains and their use in polyurethane synthesis. Bull. Chem. Soc. Jpn. 71, 1477-1482 (1998).

Acknowledgments This research was funded by the European Research Council (Advanced grant no. 339019). The authors thank the EPSRC National Mass Spectrometry Service Centre (Swansea, U.K.) for high-resolution mass spectrometry. DAL is a Royal Society Research Professor. The data that support the findings of this study are available within the paper and its Supplementary Materials, or are available from the Mendeley data repository with the identifier doi 10.17632/xxxxxxxx.

\section{Supplementary Materials:}

Materials and Methods

Figures S1 to S41

NMR Spectra

References (36-38) 